ISSN $1980-0827$

\title{
Qualidade microbiológica da água do Córrego das Marrecas no município de Dracena - SP
}

Microbiological quality of the Marrecas Stream water in the municipality of Dracena-SP Calidad microbiológica del agua del Arroyo de las Marrecas en el municipio de Dracena-SP

\author{
Osmar Pereira da Silva Junior \\ Mestrando, UNESP - Ilha Solteira/SP, Brasil \\ engosmar1992@gmail.com \\ Sergio Luís de Carvalho \\ Professor Doutor, UNESP, Brasil \\ sergicar@bio.feis.unesp.br
}

Juliana Heloisa Pinê Américo-Pinheiro Professora Doutora do PPGEC, UNESP - Ilha Solteira/SP, Brasil. americo.ju@gmail.com 


\section{RESUMO}

Este trabalho se propôs a analisar a ocorrência da Escherichia coli do grupo coliformes que são utilizados como indicadores de poluição fecal, no Córrego das Marrecas no município de Dracena - SP, este córrego tem sua nascente dentro do perímetro urbano, local em que é canalizado por uma galeria até o perímetro rural onde recebe o efluente de uma estação de tratamento de esgoto, foram realizadas duas coletas, uma no mês de abril e outra no mês de maio de 2017 em cinco pontos, um ponto próximo a nascente, outro antes do lançamento do efluente, um imediatamente após o lançamento, outro a jusante do lançamento e o último na foz do córrego no município de Panorama - SP, os pontos foram os mesmos nas duas coletas. Após as análises verificou-se a existência da Escherichia coli em todos os pontos em ambas as coletas. De acordo com os resultados obtidos neste trabalho, os valores de E. coli estão acima dos recomendados pela Cetesb. Pode-se concluir que os principais condicionantes para os valores mais altos de Escherichia coli encontrados neste córrego é o lançamento de efluente da estação de tratamento de esgoto, água de drenagem urbana e o contato direto com a tubulação de águas residuais que pode apresentar vazamentos contaminando a nascente.

Palavras - chave: Coliformes, Escherichia coli. Qualidade da água.

\section{ABSTRACT}

This work aimed to analyze the occurrence of Escherichia coli from the group of coliforms that are used as indicators of fecal pollution, in the Marrecas Stream in the municipality of Dracena - SP, this stream has its source within the urban perimeter, where it is channeled through A gallery to the rural perimeter where it receives the effluent from a sewage treatment plant, two collections were carried out, one in the month of April and another in the month of May of 2017 in five points, one point near the source, another before the launch Of the effluent, one immediately after the launch, another downstream of the launch and the last at the mouth of the stream in the municipality of Panorama - SP, the points were the same in the two collections. After the analyzes the existence of Escherichia coli was verified at all points in both collections. According to the results obtained in this work, the values of $E$. coli are above those recommended by Cetesb. It can be concluded that the main constraints to the higher Escherichia coli values found in this stream are the effluent discharge from the sewage treatment plant, urban drainage water and direct contact with the wastewater pipeline which may present leaks contaminating the spring.

Key words: Coliforms, Escherichia coli. Water quality.

\section{RESUMEN}

Este trabajo se ha propuesto como un análisis de la situación de Escherichia coli del grupo coliformes que se utilizan como indicadores de fecal pecuaria, no Córrego das Marrecas no município de Dracena - SP, este córrego tem su nascente en el perímetro urbano, local em que é canalizado por Una vez que el perímetro rural se recibe el efluente de una estación de tratamiento de esgoto, se llevaron a cabo dos coletas, una no mes de abril y otro no mes de mayo de 2017 Hacer el lanzamiento, el lanzamiento y el último en el censo de no panorama de Panorama - SP, los puntos para los dos nas dos coletas. Después de que los análises verificou-se una existencia de Escherichia coli en todos los puntos en ambas como coletas. De acuerdo con los resultados obtidos en este trabajo, los valores de E. coli fueron confirmados por Cetesb. Puede encontrar los principales condicionantes para los valores más altos de Escherichia coli en este córrego, el lanzamiento de efluente de estación de tratamiento de esgoto, el agua de drenaje urbana y el contacto directo con una tubería de aguas residuales que pueden presentar fugas contaminando a nascente.

Palabras clave: Coliformes. Escherichia coli. Calidad del agua. 


\section{INTRODUÇÃO}

O crescimento demográfico e o desenvolvimento socioeconômico são frequentemente acompanhados de aumentos na demanda por água, cuja quantidade e qualidade são de fundamental importância para a saúde e o desenvolvimento de qualquer comunidade (BUENO et al., 2005). A utilização da água para determinado propósito não deve prejudicar os diversos usos possíveis, entre os quais figuram as atividades de consumo humano, produção agropecuária, recreativas e a preservação da diversidade biológica. Em consequência, é necessário monitorar os cursos hídricos, a fim de disponibilizar informações que permitam propor medidas de manejo para manter os ambientes aquáticos com qualidade ecológica (STRIEDER et al., 2003). Assim, para assegurar o gerenciamento sustentável dos recursos hídricos e seus múltiplos usos, a avaliação da qualidade da água em uma bacia hidrográfica é de fundamental importância (STRIEDER et al., 2006).

A qualidade da água tornou-se uma questão de saúde pública no final do século XIX e início do século XX, devido à compreensão da relação água contaminada e doença. As doenças de veiculação hídrica são caracterizadas principalmente pela ingestão de água contaminada por microrganismos patogênicos de origem entérica, animal ou humana, transmitidos basicamente pela rota fecal-oral (DOMINGUES et al, 2007). Esses microrganismos, simplesmente, requerem o mínimo de condições para sobreviver nas condições mais diversas (DROSTE, 1997). Segundo Sperling (1996), os microrganismos desempenham diversas funções de fundamental importância, principalmente as relacionadas com a transformação da matéria dentro dos ciclos biogeoquímicos, sendo que o aspecto de maior relevância em termos da qualidade biológica da água é relativo à possibilidade da transmissão de doenças.

A determinação da potencialidade de uma água transmitir doenças pode ser avaliada de forma indireta, por meio dos organismos indicadores de contaminação fecal, pertencentes principalmente ao grupo dos coliformes, sendo a principal indicadora desse grupo a bactéria Escherichia coli (BARBOSA et al., 2009).

Os coliformes atualmente denominados de termotolerantes, segundo a Resolução CONAMA no 375 de 17 de março de 2005, são: “Bactérias gram-negativas, em forma de bacilos, oxidasenegativas, caracterizadas pela atividade da enzima $\beta$-galactosidase. Podem crescer em meios contendo agentes tenso-ativos e fermentar a lactose nas temperaturas de $440-45 \circ \mathrm{C}$, com produção de ácido, gás e aldeído. Além de estarem presentes em fezes humanas e de animais homeotérmicos, ocorrem em solos, plantas ou outras matrizes ambientais que não tenham sido contaminados por material fecal.

A Escherichia coli é a única que vive no intestino humano, vale destacar que não causa problemas à saúde quando está no intestino, pois é uma bactéria normal nesse local. Entretanto, algumas variantes podem desencadear distúrbios gastrointestinais caracterizados por diarreia aquosa. A determinação da concentração dos coliformes assume importância como parâmetro indicador da possibilidade da existência de microrganismos patogênicos, responsáveis pela transmissão de doenças de veiculação hídrica tais como cólica, febre, diarréia, calafrios, mal estar, e às vezes quadro de diarréia com sangramento (BARBOSA et al., 2009). O NMP é o número mais provável de bactérias coliformes por 100 mililitros de amostra. 
De maneira geral, pode-se afirmar que a maior parte desses microrganismos não é patogênica e são utilizados apenas como indicadores da potencialidade de contaminação fecal com a possível presença de patogênicos (CAMPOS, 2000).

\section{OBJETIVOS}

O objetivo deste trabalho foi determinar a qualidade microbiológica da água considerando a concentração de Escherichia coli em amostras de água do Córrego das Marrecas no município de Dracena - SP.

\section{MATERIAL E MÉTODOS}

O Córrego das Marrecas tem sua nascente no município de Dracena- SP e sua foz na cidade de Panorama- SP, como mostrado na Figura 1.

Figura 1: Localização da bacia hidrográfica do córrego das marrecas no município de Dracena - SP

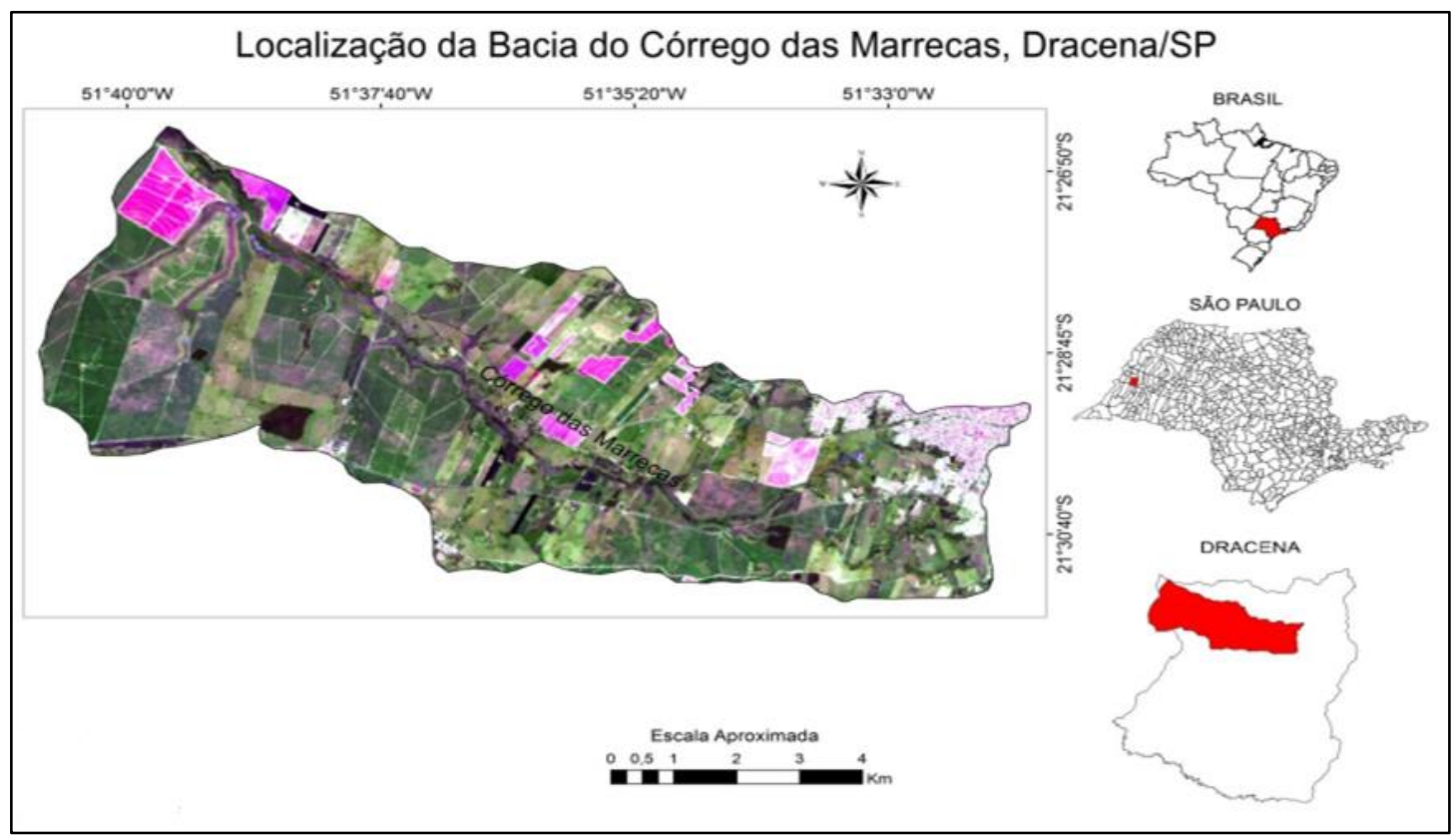

Fonte: MEDEIROS ; MIGUEL; BRUGMOLLI (2014).

As amostras foram coletadas nos meses de abril e maio de 2017 em cinco pontos do Córrego das Marrecas $\mathrm{O}$ primeiro ponto (P1) de amostragem foi o mais próximo possível da nascente, como o córrego tem sua nascente dentro do perímetro urbano e abaixo das edificações o mesmo é canalizado por uma galeria até o perímetro rural do município, por esta mesma galeria também passa a tubulação de água residuária, como mostra a Figura 2.

O segundo ponto (P2) localiza-se a montante do lançamento do efluente da estação de tratamento de esgoto, o terceiro ponto (P3) encontra-se imediatamente após o lançamento do 
efluente, o quarto ponto (P4) fica a jusante do lançamento e o quinto ponto (P5) fica localizado na foz do Córrego das Marrecas que fica no município de Panorama - SP (Tabela 1).

Figura 2: Galeria que canaliza a nascente do córrego das marrecas juntamente com a tubulação de águas residuais no município de Dracena - SP

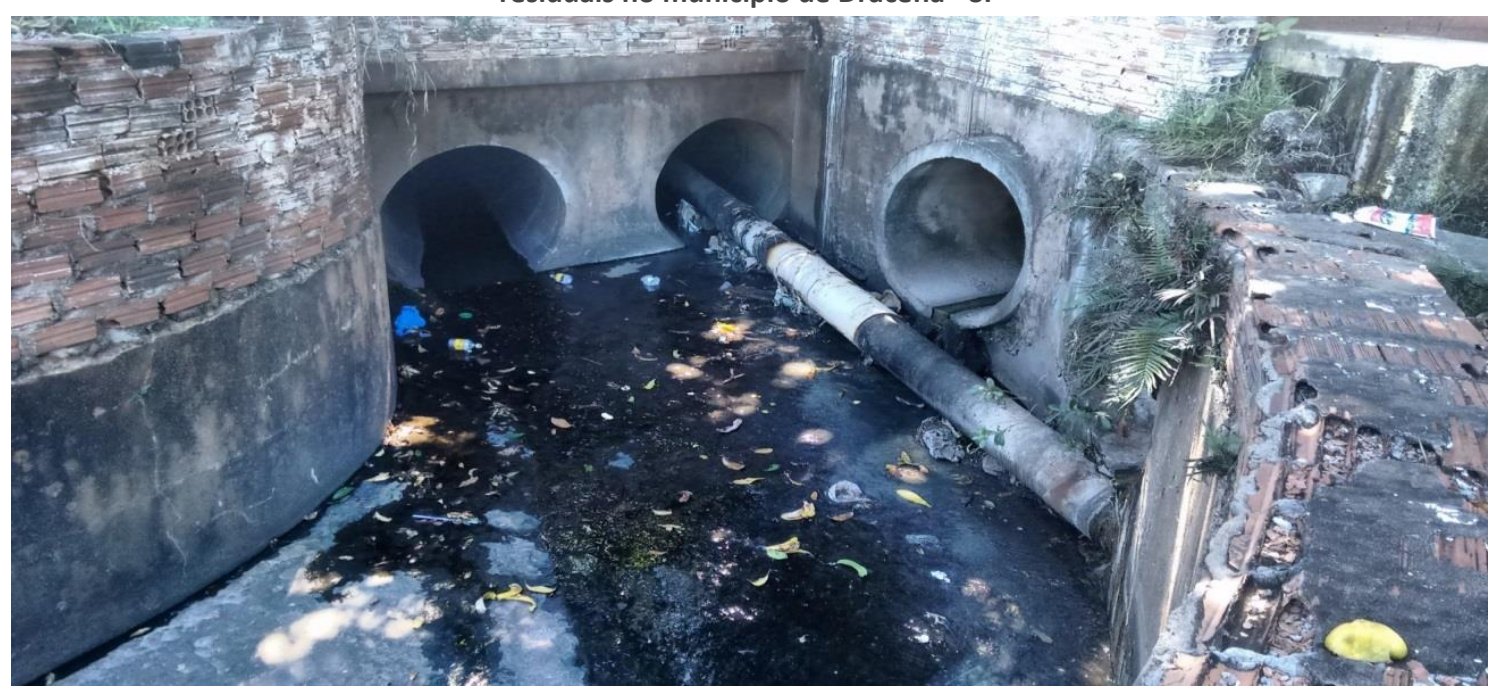

Tabela 1: Descrição dos pontos de amostragem do Córrego das Marrecas no município de Dracena - SP e suas respectivas coordenadas geográficas.

\begin{tabular}{|c|c|c|c|}
\hline \multirow{2}{*}{$\begin{array}{c}\text { Pontos de } \\
\text { Amostragem }\end{array}$} & \multirow{2}{*}{ Descrição da Localização } & \multicolumn{2}{|c|}{ Coordenadas Geográficas } \\
\hline & & Latitude & Longitude \\
\hline P1 & Nascente do córrego das Marrecas & S $21^{\circ} 29^{\prime} 27,7^{\prime \prime}$ & W $51^{\circ} 32^{\prime} 18,1^{\prime \prime}$ \\
\hline $\mathrm{P} 2$ & Antes do lançamento de efluente tratado da ETE & $\mathrm{S} 21^{\circ} 29^{\prime} 52,4^{\prime \prime}$ & W 51 $31^{\circ} 19,9^{\prime \prime}$ \\
\hline P3 & Lançamento do efluente tratado da ETE & $\mathrm{S} 21^{\circ} 30^{\prime} 11,8^{\prime \prime}$ & W $51^{\circ} 33^{\prime} 53,4^{\prime \prime}$ \\
\hline P4 & Jusante da ETE & $\mathrm{S} 21^{\circ} 29^{\prime} 19,5^{\prime \prime}$ & W $51^{\circ} 36^{\prime} 46,2^{\prime \prime}$ \\
\hline P5 & Foz do córrego das Marrecas & $\mathrm{S} 21^{\circ} 21^{\prime} 04,2^{\prime \prime}$ & W $51^{\circ} 51^{\prime} 05,0^{\prime \prime}$ \\
\hline
\end{tabular}

Em cada ponto de amostragem foi coletado $1 \mathrm{~L}$ de água superficial que foram armazenadas em frascos âmbar previamente lavados e secos à temperatura ambiente. As amostras foram transportadas em caixas térmicas contendo gelo para serem analisadas no Laboratório de Saneamento da Faculdade de Engenharia de Ilha Solteira.

A metodologia de análise utilizado foi o método de placas Petrifilm para Contagem de E. coli e Coliformes, essas placas contêm nutrientes do meio Vermelho Violeta Bile (VRB).

Um agente geleificante solúvel em água fria, um indicador de atividade glicuronidásica e um indicador que facilita a enumeração da colônia. A maioria das E.coli (cerca de 97\%) produz beta-glicuronidase na qual forma um precipitado azul associado a colônia. O filme superior retém o gás formado pelos coliformes e $E$. coli que são fermentadores de lactose. Cerca de $95 \%$ das $E$. coli produzem gases que são indicados pelas colônias azuis a vermelho-azuladas, associadas ao gás retido na placa Petrifilm dentro de, aproximadamente o diâmetro de uma colônia. Para realizar a análise foi necessário diluir as amostras do ponto 1 e 3 devido a suspeita de uma maior concentração de E.coli, para os pontos 2, 4 e 5 utilizou - se as amostras 
naturais sem diluição. Após a realização do processo descrito, as placas Petrifilm foram incubadas em uma estufa bacteriológica com uma temperatura de $35^{\circ} \mathrm{C} \pm 2{ }^{\circ} \mathrm{C}$ por um período de 48 horas.

Depois do período de incubação as colônias de Escherichia coli aparecem nas placas Petrifilm com uma coloração azulada, podendo assim através de uma contagem determinar a quantidade de colônias em cada placa.

\section{RESULTADOS E DISCUSSÃO}

Os resultados das duas coletas em relação a Escherichia coli estão expressos na Tabela 1, as concentrações elevadas no ponto 1 pode - se atribuir ao fato da tubulação de esgoto passar pela mesma galeria que canaliza a nascente do Córrego, podendo haver contaminação da água por algum vazamento que possa existir na tubulação de esgoto. No ponto 3 as concentrações elevadas de Escherichia coli deve - se ao lançamento do efluente da estação de tratamento de esgoto.

O ponto 2 fica próximo ao perímetro urbano da cidade de Dracena - SP, e recebe um grande volume de água pluvial, este fato pode estar associado as concentrações encontradas nesse ponto. Para as concentrações encontradas no ponto 4 atribui - se o fato de que este ponto fica distante do perímetro urbano e do lançamento do efluente, portanto não há uma contaminação direta nesse ponto. Já para o ponto 5 na cidade de Panorama - SP as concentrações encontradas de Escherichia coli deve estar relacionada com o grande volume de água que o Córrego das Marrecas tem nesse local, diminuindo assim a concentração de Escherichia coli nesse ponto.

Tabela 1: Valores do número mais provável (NMP) de Escherichia coli (NMP/100mL) encontrado nos diferentes pontos de coleta, nos meses de abril e maio de 2017

\begin{tabular}{lccccc}
\hline $\begin{array}{l}\text { Quantificação das } \\
\text { colônias de } E \text {. coli }\end{array}$ & Ponto 1 & Ponto 2 & Ponto 3 & Ponto 4 & Ponto 5 \\
\hline Primeira coleta & 22000 & 5000 & 13000 & 500 & 200 \\
\hline Segunda coleta & 8000 & 1700 & 72000 & 1900 & 2200 \\
\hline
\end{tabular}

O córrego em estudo tem como finalidade principal a dessedentação de animais, de acordo com a Cetesb (2005), para dessedentação de animais criados confinados não deverá ser excedido o limite de 1000 coliformes termotolerantes por 100 mililitros em $80 \%$ ou mais de pelo menos 6 amostras, coletadas durante o período de um ano, com frequência bimestral. Para os demais usos, não deverá ser excedido um limite de 4000 coliformes termotolerantes por 100 mililitros em $80 \%$ ou mais de pelo menos 6 amostras coletadas durante o período de um ano, com periodicidade bimestral. A E. coli poderá ser determinada em substituição ao parâmetro coliformes termotolerantes. 


\section{CONCLUSÃO}

De acordo com os resultados obtidos neste trabalho, os valores de $E$. coli estão acima dos recomendados pela Cetesb e podem causar prejuízos a qualidade da água do córrego.

Pode-se concluir que os principais condicionantes para os valores mais altos de Escherichia coli encontrados neste córrego é o lançamento de efluente da estação de tratamento de esgoto, água de drenagem urbana e o contato direto com a tubulação de águas residuais que pode apresentar vazamentos contaminando a nascente.

\section{AGRADECIMENTOS}

À Coordenação de Aperfeiçoamento de Pessoal de Nível Superior (CAPES) pela bolsa de mestrado do primeiro autor.

\section{REFERÊNCIAS BIBLIOGRÁFICAS}

BARBOSA D. B, et al. Qualidade microbiológica da água dos bebedouros de um Campus universitário de Ipatinga, Minas Gerais. NUTRIR GERAIS - Revista Digital de Nutrição, Ipatinga, v. 3, n. 5, p. 505-517, ago./dez. 2009. BUENO, L.F.; GALBIATTI, J.A.; BORGES, M.J. Monitoramento de variáveis de qualidade de água no horto Ouro Verde - Conchal - SP. Engenharia Agrícola, Jaboticabal, v.25, n.3, p.742-748, 2005.

CAMPOS, J.R. O saneamento básico no Brasil. In: CASTELLANO, E.G.; F.H. CHAUDRY (Eds.). Desenvolvimento sustentável: problemas e estratégias. São Carlos: EESC-USP, 2000. p.7-25.

CETESB- Companhia de Tecnologia de Saneamento Ambiental - Relatório de Qualidade das Águas Interiores do Estado de São Paulo-2005. Disponível em: www.cetesb.sp.gov.br. Acesso em: 02/Jun./2017.

CQA QUÍMICA. Placas Petrifilm 3M para contagem coliformes com diferenciação em E. coli (EC). Disponível em: < http://site.cqaquimica.com.br/microbiologia/placas-prontas-para-uso/placas-petrifilm-3m-para-contagemcoliformes-com-diferenciacao-em-e-coli-ec/>. Acesso em: 15 Jun 2017.

CONAMA - CONSELHO NACIONAL DO MEIO AMBIENTE. (2005) Resolução no 357, de 17 de marco de 2005. Dispõe sobre a classificação dos corpos de água e diretrizes ambientais para o seu enquadramento, bem como estabelece as condições e padrões de lançamento de efluentes, e dá outras providências. Brasília: Diário Oficial da União; 2005. Disponível em: <http://www.mma.gov.br>. Acesso em: 15/ jun. 2017.

DOMIngues, V. O. et al. Contagem De Bactérias Heterotróficas Na Água Para Consumo Humano:. Saúde, Santa Maria, vol 33, n 1: p 15-19, 2007

DROSTE, R. L. Theory and practice of water and wastewater treatment. Washington: Congress Cataloging-inPublication Data, 1997, p.132-136.

MEDEIROS, R. B.; MIGUEL, A. E. S.; BRUGMOLLI, C. A. C. Caracterização Fisiográfica da Bacia Hidrográfica do Córrego das Marrecas, Dracena/SP. X Fórum Ambiental da Alta Paulista, Tupã, v. 10, n. 2, p. 41-56, 2014.

SPERLING, M. V. Introdução à qualidade das águas e ao tratamento de esgotos. 2. ed. Belo Horizonte: Escola de Engenharia da UFMG, 1996. 243p.

STRIEDER, M.N.; RONCHI, L.H.; NEISS, U.G.; OLIVEIRA, M.Z. Avaliação dos efeitos de fontes de poluição pontual sobre os macroinvertebrados bentônicos no Arroio Peão, RS. In: RONCHI, L.H.; COELHO, O.G.W. Tecnologia, diagnóstico e planejamento ambiental. São Leopoldo: Unisinos, 2003. p.61-85. 
STRIEDER, M.N.; RONCHI, L.H.; STENERT, C.; SCHERER, R.T.; NEISS, U.G. Medidas biológicas e índices de qualidade da água de uma microbacia com poluição urbana e de curtumes no Sul do Brasil. Acta Biológica Leopoldensia, Porto Alegre, v.28, n.1, p.17-24, 2006. 